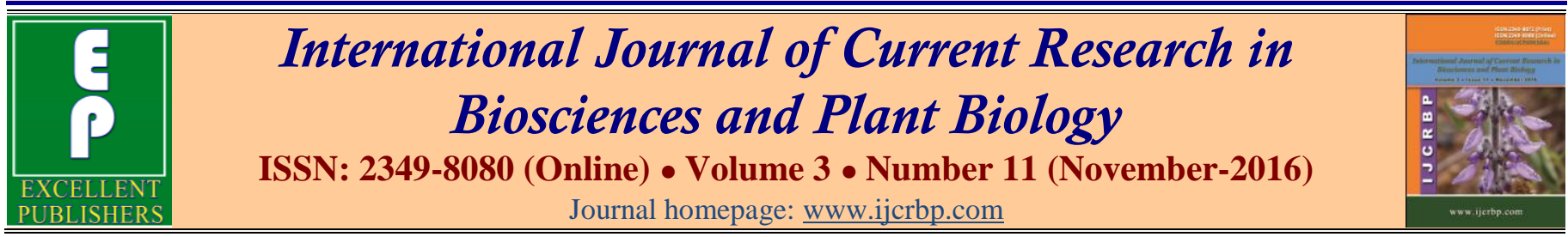

\title{
Study of Synergy between Mentha pulegium Essential Oil, Honey and Bacteriocin-like Inhibitory Substance E204 against Listeria monocytogenes CECT 4032 and Escherichia coli K12
}

\author{
El Ouardy Khay $^{{ }^{*}}$, Abdelhakim Bouyahya ${ }^{1,2}$, Kaoutar El Issaoui ${ }^{1}$, Sanae Zinebi ${ }^{1}$ and \\ Jamal Abrini ${ }^{1}$
}

${ }^{1}$ Biology and Health Laboratory, Team of Biotechnology and Applied Microbiology, Faculty of Science, Abdelmalek Essaadi University, Tetouan, Morocco

${ }^{2}$ Biochemistry Immunology Laboratory, Faculty of Sciences, Mohammed V University, Rabat, Morocco

*Corresponding author.

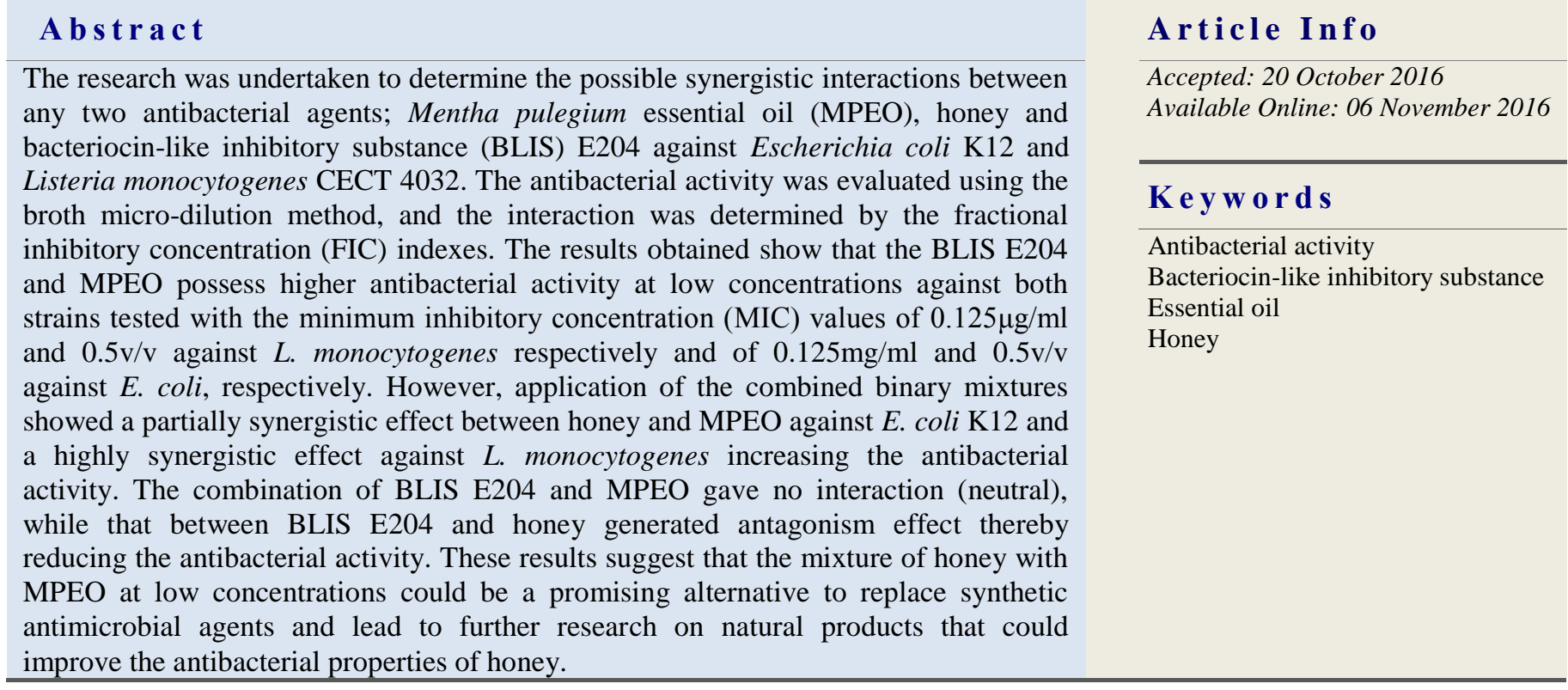

\section{Introduction}

Since the discovery of antibiotics, the man knows a real success in the fight against infectious diseases. Indeed, antibiotics could reduce the morbidity rate of the world population. However, the coevolution of human-microbe interface led to the appearance and the emergence of multi-drug resistance of some bacterial populations, causing a major problem for public health (Bandow et al., 2003). The situation is particularly worrying in hospitals and food due to the colonization of the surface of the implant and prosthetic infections (Guerrero et al., 2009). In addition, infectious diseases caused by resistant microorganisms are associated with prolonged hospital stays, higher costs, and increased risk of morbidity and mortality. 
However, the resistance of many bacteria to antimicrobial agents, detergents and disinfectants is a major global problem in different areas, such as food (Budka and Khan, 2010; Kumar et al., 2008), paper industry (Bernier et al., 1986) and environment (Smith et al., 1994). Moreover, looking for new antimicrobial substances as alternatives to fight against the problem of resistance to microorganisms is a line of very promoter research.

More recently, research is increasingly oriented towards the screening of natural products, especially plant extracts such as essential oils to screen for substances with antimicrobial properties. These products have been used for many years but their use was purely empiric.

Nowadays, essential oils and some of their main components are used in the manufacture of perfumes and flavoring agents in foods and beverages (Jafari et al., 2011). In recent years, essential oils have shown powerful biological properties such as antimicrobial activity (Kamazeri et al., 2012) and antioxidant activity (Gardeli et al., 2008; Abed et al., 2011; Aidi Wannes et al., 2010). However, the activity of the essential oil in combination with other agents is poorly reported. Mentha pulegium $\mathrm{L}$. is a plant belonging to the family of Lamiaceae and is heavily used in Moroccan traditional medicine. The essential oils from this plant have been shown effective for their antibacterial activity (Mahboubi and Haghi, 2008; Derwich et al., 2010; Ait-Ouazzou et al., 2012) and antioxidant activity (Sitzmann et al., 2014; Ouakouak et al., 2015; Brahmi et al., 2016).

Over thousands of years, honey has been used for medicinal applications. The beneficial effects of honey, especially its antimicrobial activity makes it a useful option to defend the different pathologies. Honey contains large amounts of carbohydrates, lipids, amino acids, proteins, vitamins and minerals that have an important role in wound healing. Because bees have different nutritional behavior and collect nutrients from diverse and varied plants, honey products have different compositions. Thereby, different types of honey have different medicinal value leading to different biological effects. Honey and its various compounds have shown antimicrobial effects (Oryan et al., 2007; Manyi-Loh et al., 2011; Wasiak et al., 2013), anti-inflammatory effect (Molan, 2002; Singh et al., 2011; Yaghoobi et al., 2013; Majtan, 2014), antioxidant effects (Singh et al., 2011), stimulatory effects of the immune system (Al-Waili et al., 2011; Majtan, 2014) and stimulation of tissue regeneration (Oryan and Zaker, 1998; Molan, 2002).

Bacteriocins are proteins or protein complexes with bactericidal activity against species that are closely related to the producer strain (Klaenhammer, 1988). The bacteriocins, produced by lactic acid bacteria, are low molecular weight antimicrobial peptides. Their spectrum of activity is generally narrow. However, most have activity against foodborne pathogens such as Listeria monocytogenes. The camel milk is very rich in lactic acid bacteria capable of producing bacteriocin. Indeed, Enterococcus durans E204 is a strain isolated from camel milk of Laayoune region (Morocco). This bacterial strain produces a bacteriocin-like inhibitory substance (BLIS) E204 that has been characterized and shown effective in inhibiting pathogenic bacterial strains (Khay et al., 2011). The application of BLIS E204 for the control of the pathogenic and food spoilage organisms has been investigated in milk and cheese (Khay et al., 2013; Khay et al., 2014).

In this work, we proposed to study the combined effects of binary mixtures of MPEO, honey and BLIS E204 against two bacterial strains $E$. coli $\mathrm{K} 12$ and $L$. monocytogenes CECT 4032.

\section{Materials and methods}

\section{Essential oil}

Mentha pulegium was collected from Ouezzane region (Morocco), identified by Dr. Abdessalam ENNABILI (National Institute of Medicinal and Aromatic Plants, Taounate, Morocco). The essential oil was extracted by steam distillation from the flowering tops of the plant.

\section{Honey}

Honey is collected from the province of Ouezzane (Morocco).

\section{Bacteriocin-like inhibitory substance (BLIS) E204}

BLIS E204 was produced by Enterococcus durans E204 isolated from camel milk of Morocco (Khay et al., 2011). Briefly, cells were harvested from 11 culture in MRS Broth by centrifugation $\left(15000 \mathrm{~g}, 10 \mathrm{~min}, 4^{\circ} \mathrm{C}\right)$ after $16 \mathrm{~h}$ of incubation at $30^{\circ} \mathrm{C}$. The cell free culture supernatant, adjusted to pH 6.5 (with $10 \mathrm{M} \mathrm{NaOH}$ ), was subjected for $90 \%$ ammonium sulphate precipitation overnight at $4^{\circ} \mathrm{C}$. The precipitated sample was suspended in $50 \mathrm{mM}$ sodium 
phosphate buffer $(\mathrm{pH}$ 6.5) and tested positive for the presence of antibacterial activity. The suspended precipitate was dialyzed against ultrapure Milli-Q water. The obtained fraction was considered as the crude BLIS E204 used in this study.

\section{Bacterial strains}

Listeria monocytogenes CECT 4032 obtained from the Spanish Type Culture Collection (CECT) and Escherichia coli $\mathrm{K} 12$ from the Laboratory of Food Microbiology, UCL, Belgium (MBLA) were used as test microorganisms. Stock cultures were kept on LuriaBertani (LB) Agar slants under refrigeration $\left(4^{\circ} \mathrm{C}\right)$. Inocula used in antibacterial assays were obtained from overnight cultures grown on LB broth slants at $37^{\circ} \mathrm{C}$.

\section{Determination of minimum inhibitory concentration}

The minimum inhibitory concentration (MIC) was determined by the micro-dilution method. This technique involves inoculating, by a standardized inoculum, a range of decreasing concentrations of the products tested. After incubation, the observation of the range allows access to the MIC, which is the lowest concentration of the tested product able to inhibit bacterial growth. Briefly, in a micro-dilution plate containing 96 wells, serial dilution of the essential oil, honey or BLIS E204 were prepared in DMSO. Then, each well was filled with $50 \mu \mathrm{l}$ of LB medium at $0.15 \%$ agar inoculated from a bacterial culture in exponential growth phase in order to obtain a final cell concentration of approximately $10^{6} \mathrm{cfu} / \mathrm{ml}$.

The wells as a control did not contain the product tested. The plates were then incubated at the appropriate temperature for growth of the germ $\left(37^{\circ} \mathrm{C}\right)$ for $18 \mathrm{~h}$. The MIC corresponds to the small concentration of the product at which no growth was detected. For the determination of the MIC, $10 \mu \mathrm{l}$ of resazurin was added to each well. After $2 \mathrm{~h}$ of incubation, the MIC corresponds to the lowest essential oil concentration that does not produce resazurin discoloration.

\section{Determination of fractional inhibitory concentration}

The interaction effect between the essential oil and honey, essential oil and BLIS E204, and honey and BLIS E204 was determined by adopting the method of Ouedrhiri et al. (2015) with minor modifications. The concentration of the essential oil is prepared in LB medium supplemented with $0.15 \%$ agar, while the concentrations of honey and BLIS E204 are prepared with DMSO to $10 \%$.

\section{Synergy between MPEO and honey}

In a plate containing 96 wells, series of two-fold dilutions of MPEO were prepared in the abscissa from the first to second wells with concentrations of $16 \times \mathrm{MIC}$ up the MIC/128. In the axis of coordinated are added concentrations of the honey from the first to seventh well (4×MIC until MIC/16). The eighth well, not containing the product corresponds to the control. After, a bacterial inoculum (approximately $10^{6} \mathrm{cfu} / \mathrm{ml}$ ) is placed in each well. The plates are then incubated at the appropriate temperature for growth of the germ $\left(37^{\circ} \mathrm{C}\right)$ for $18 \mathrm{~h}$. The MIC corresponds to the small concentration of the product in combination which produces no bacterial growth. For the determination of the MIC, $10 \mu \mathrm{l}$ of resazurin are added to each well. After $2 \mathrm{~h}$ of incubation, the MIC corresponds to the lowest essential oil concentration that does not produce resazurin discoloration.

\section{Synergy between MPEO and BLIS E204}

In a plate containing 96 wells, series of two-fold dilutions of MPEO have been prepared in the $\mathrm{x}$-axis from the first to eleventh wells with concentrations of $8 \times \mathrm{MIC}$ up to MIC/128. In the axis of coordinates, are added concentrations of the BLIS E204 from the first to seventh well (4×MIC until MIC/16). The second well corresponds to the control. After, a bacterial inoculum (approximately $10^{6} \mathrm{cfu} / \mathrm{ml}$ ) is placed in each well. The plates are then incubated at the appropriate temperature for growth of the germ $\left(37^{\circ} \mathrm{C}\right)$ for $18 \mathrm{~h}$. The MIC corresponds to the small concentration of the product which does not produce bacterial growth.

\section{Synergy between honey and BLIS E204}

In a plate containing 96 wells, series of two-fold dilutions of BLIS E204 were prepared in the abscissa from the first to eleventh wells with concentrations of $8 \times$ MIC up the MIC/128. In the axis of coordinated are added concentrations of honey from the first to seventh well (4×MIC until MIC/16). The second well corresponds to the control. After, a bacterial inoculum (approximately $10^{6} \mathrm{cfu} / \mathrm{ml}$ ) is placed in each well. The plates are then incubated at the appropriate temperature for growth of the germ $\left(37^{\circ} \mathrm{C}\right)$ for $18 \mathrm{~h}$. The MIC corresponds to the small concentration of the product in combination which produces no bacterial growth. 
The fractional inhibitory concentration index (FICI) is calculated by the following formula:

$\sum \mathrm{FICI}=\mathrm{FIC}(\mathrm{A})+\mathrm{FIC}(\mathrm{B})$

$$
\begin{aligned}
& \text { FIC (A) }=\frac{\text { MIC (A) in combination }}{\text { MIC (A) alone }} \\
& \text { FIC (B) }=\frac{\text { MIC (B) in comination }}{\text { MIC (B) alone }}
\end{aligned}
$$

The index values of the fractional inhibitory concentrations are interpreted as following: FICI $\leq 0.5=$ Synergy; FICI $<0.5-0.75 \geq$ = partial Synergy; FICI $\leq 0.76$ 1.0> = Additive; FICI $>1-4 \leq=$ No interaction (not differential) and FICI $>4=$ Antagonism.

\section{Results}

\section{Minimum inhibitory concentrations (MIC)}

The minimum inhibitory concentration was determined by the microdilution in microtiter plate. The results of the effect of MPEO, honey and BLIS E204 are shown in Table 1. From the results, the three products showed antibacterial activity against the two strains tested. With the exception of the essential oil, L. monocytogenes $($ Gram +$)$ is more sensitive towards BLIS E204 and honey than E. coli (Gram -). The lowest MIC value was recorded with the effect of BLIS E204 against L. monocytogenes $(0.0625)$.

Table 1. Minimum inhibitory concentration of the products

\begin{tabular}{|c|c|c|}
\hline \multirow{3}{*}{ Product tested } & \multicolumn{2}{|l|}{$\mathrm{MIC}^{\mathrm{ab}}$} \\
\hline & Bacteri & \\
\hline & E. coli & L. monocytogenes \\
\hline BLIS E204 & 0.125 & 0.0625 \\
\hline MPEO & 0.5 & 0.5 \\
\hline Honey & 5 & 2.5 \\
\hline
\end{tabular}
tested.

\section{Fractional inhibitory concentration (FIC)}

The results of synergistic effects between MPEO and honey, MPEO and BLIS E204, and honey and BLIS E204 are presented in Table 2. The results reveal the existence of different synergistic actions. MPEO and honey produced positive interaction with a partial synergistic against $E$. coli and synergy against L. monocytogenes. The MPEO with BLIS E204 shows no interaction. While BLIS E204 with honey generated a negative interaction giving an antagonistic effect against the two strains tested.

Table 2. Fractional inhibitory concentrations.

\begin{tabular}{lllllll}
\hline \multirow{2}{*}{ Strain } & \multirow{2}{*}{ Product } & MIC & & \multirow{2}{*}{ FIC } & \multirow{2}{*}{ FICI } & \multirow{2}{*}{ Result } \\
\cline { 3 - 4 } & MPEO & 0.5 & 0.25 & 0.5 & 0.575 & Partial synergy \\
& Honey & 5 & 2.5 & 0.25 & & \\
& MPEO & 0.5 & 0.5 & 1 & 2 & No interaction \\
& BLIS E204 & 0.125 & 0.125 & 1 & & \\
& Honey & 5 & 2.5 & 0.5 & 4.5 & Antagonism \\
& BLIS E204 & 0.125 & 0.5 & 4 & & \\
L. monocytogenes & MPEO & 0.5 & 0.125 & 0.25 & 0.375 & Synergy \\
& Honey & 2.5 & 0.3125 & 0.125 & & \\
& MPEO & 0.5 & 0.125 & 0.25 & 1.25 & No interaction \\
& BLIS E204 & 0.0625 & 0.0625 & 1 & & \\
& Honey & 2.5 & 1.25 & 0.25 & 4.25 & Antagonism \\
\hline
\end{tabular}

MIC: minimum inhibitory concentration; FIC: Fractional inhibitory concentration; MPEO: Mentha pulegium essential oil; BLIS: bacteriocin-like inhibitory substance. FICI : Fractional inhibitory concentration index.

\section{Discussion}

Antibiotic resistance suggests different sources for other molecules that can be alternatives to fight against infectious diseases. The various alternative ways are sought. In Morocco, as in other African countries, herbal medicine either herbs or honey is most commonly used to combat infectious diseases such as diarrhea. Essential oils are volatile substances produced by aromatic plants. They have proven effective in several biological 
activities including antibacterial activity. However, the use of essential oils directly into phytotherapy is not recommended and people often use the whole plant or a part of the plant (drug). Moreover, honey is highly recommended as a food in the therapeutic Moroccan tradition.

In the present study we looked the synergistic effects between MPEO and honey, MPEO and BLIS E204, and honey and BLIS E204. The three products were shown antibacterial activity against both strains tested (E. coli and L. monocytogenes). BLIS E204 and MPEO inhibited both bacteria tested at significantly lower minimum inhibitory concentration than that obtained with the honey. The difference in activity is certainly related to the difference in chemical terms between the three products tested. The essential oil of $M$. pulegium has been proven effective against $E$. coli and L. monocytogenes by several authors (Mahboubi and Haghi, 2008; Marzouk et al., 2008). Honey was shown activity against several bacterial strains including $E$. coli and L. monocytogenes (Vorlova et al., 2005; Rodriguez et al., 2012; Hussain et al., 2015). Bacteriocin has already demonstrated potent antibacterial activity against L. monocytogenes (Khay et al., 2013).

The difference in activity recorded between the two bacterial strains is due to the fact that Gram negative bacteria are more resistance to antibacterial molecules than Gram positive bacteria. This resistance is primarily due to the presence in Gram negative bacteria of a wall rich in lipopolysaccharides (LPS) an outer membrane which blocks the permeation of the antibacterial molecules (Inouye et al., 2001). Indeed, the bacterial wall of E. coli, for example, is rich in lipopolysaccharide (LPS) that prevent hydrophobic molecules pass through the membrane (Sharif et al., 2009).

The synergistic study between the three products tested, two by two, generated three types of interactions: Partial synergistic and synergistic effect, antagonistic effect and neutral effect (no interaction). MPEO with honey gave a partial synergistic effect against $E$. coli and a synergistic effect against $L$. monocytogenes. Unlike the results obtained is attributed to the difference of the structure between the two strains tested. BLIS E204 and honey have no interaction against both bacteria; this can be due to the nature of action of products which is the same which gave similar result for every single product tested. Another type of interaction is the antagonistic effect obtained between MPEO and BLIS E204. Indeed, the MIC values were reduced when the mixture of two products was tested. This suggests that there are inhibitory effects which occur between some compounds of MPEO and BLIS E204.

Looking for synergistic effects is a pretty exciting research axis for ethnopharmacological studies. Indeed, the ethnopharmacological researches in Morocco and even in other countries have shown that the preparation methods of drugs in phytotherapy are often linked to other product known as adjuvant such as honey and juices. In this study, we came out that essential oil used with honey gave additive effects in terms of efficiency. Mixing honey with oil is, in addition to the regenerated additive effect, a mean for administering the essential oils in herbal medicine.

\section{Conclusion}

Research in herbal medicine against bacterial diseases is a research area of great importance. The use of MPEO combined with honey in herbal medicine has a significant additive effect. However, other studies are needed and making a series of combinations between honey and essential oils.

\section{Conflict of interest statement}

Authors declare that they have no conflict of interest.

\section{Acknowledgement}

Authors would like to thank Dr. Abdessalam ENNABILI (National Institute of Medicinal and Aromatic Plants, Taounate, Morocco) for further identification of plant.

\section{References}

Abed, M., Bitman-Lotan, E., Orian, A., 2011. A fly view of a SUMO-targeted ubiquitin ligase. Fly. 5(4), 340-344.

Aidi-Wannes, W., Mhamdi, B., Sriti, J., Ben Jemia, M., Ouchikh, O., Hamdaoui, G., Kchouk, M.E., Marzouk, B., 2010. Antioxidant activities of the essential oils and methanol extracts from myrtle (Myrtus communis var. italica L) leaf stem and flower. Food Chem. Toxicol. 48(5), 1362-1370.

Ait-Ouazzou, A., Lorán, S., Arakrak, A., Laglaoui, A., Rota, C., Herrera, A., Pagán, R., Conchello, P., 2012. Evaluation of the chemical composition and antimicrobial activity of Mentha pulegium, Juniperus phoenicea, and Cyperus longus essential oils from Morocco. Food Res. Int. 45, 313-319.

Al-Waili, NS., Salom, K., Butler, G., Al-Ghamdi, A.A., 2011. Honey and microbial infections: a review supporting the use of honey for microbial control. J. Med. Food. 14(10), 
1079-1096.

Bandow, J.E., Brötz, H., Leichert, L.I.O., Labischinski, H., Hecker, M., 2003. Proteomic approach to understanding antibiotic action. Antimicrob. Agents Chemother. 47(3), 948-955.

Bernier, R., Desrochers, M., Jurasek, L., 1986. Antagonistic effect between Bacillus subtilis and wood staining fungi. J. Inst. Wood Sci. 10(5), 214-216.

Brahmi, F., Abdenour, A., Bruno, M., Silvia, P., Alessandra, P., Danilo, F., Drifa, Y.G., Mahmoud-Fahmi, E., Khodir, M., Mohamed, C., 2016. Chemical composition and in vitro antimicrobial, insecticidal and antioxidant activities of the essential oils of Mentha pulegium L. and Mentha rotundifolia (L.) Huds growing in Algeria. Ind. Crop. Prod. 88, 96-105.

Budka, D., Khan, N.A., 2010. The Effect of Ocimum basilicum, Thymus vulgaris, Origanum vulgare Essential Oils on Bacillus cereus in Rice-Based Foods. EJBS. 2(1), 17-20.

Derwich, E., Benziane, Z., Boukir, A., 2010. GC/MS analysis and antibacterial activity of the essential oil of Mentha pulegium grown in Morocco. J. Agr. Biol. Sci. 6(3), 191198.

Gardeli, C., Vassiliki, P., Athanasios, M., Kibouris, T., Komaitis, M., 2008. Essential oil composition of Pistacia lentiscus L. and Myrtus communis L.: Evaluation of antioxidant capacity of methanolic extracts. Food Chem. 107(3), 1120-1130.

Guerrero, G., Amalric, J., Mutin, P.H., Sotto, A., Lavigne, J.P., 2009. Inhibition of bacterial adhesion and prevention of biofilm formation: Use of organic self-assembled monolayers on inorganic surfaces. Pathol. Biol. 57(1), 36-43.

Hussain, M.B., Hannan, A., Akhtar, N., Fayyaz, G.Q., Imran, M., Saleem, S., Qureshi, I.A., 2015. Evaluation of the antibacterial activity of selected Pakistani honeys against multidrug resistant Salmonella typhi. BMC. Complement. Altern. Med. 15, 32.

Inouye, S., Yamaguchi, H., Takizawa, T., 2001. Screening of the antibacterial effects of variety of essential oils on respiratory tract pathogens, using a modified dilution assay method. J. Infect. Chemother. 7(4), 251-254.

Jafari, S., Esfahani, S., Fazeli, M.R., Jamalifar, H., Samadi, M., Samadi, N., Najarian-Toosi, A., Shams-Ardekani, M.R., Khanavi, M., 2011. S. Antimicrobial Activity of Lime Essential Oil Against Food-borne Pathogens Isolated from Cream-filled Cakes and Pastries. Int. J. Biol. Chem. 5(4), 258-265.

Kamazeri, T.S., Samah, O.A., Taher, M., Susanti, D., Qaralleh, H., 2012. Antimicrobial activity and essential oils of Curcuma aeruginosa, Curcuma mangga, and Zingiber cassumunar from Malaysia. Asian Pac. J. Trop. Med. 5(3), 202-209.

Khay, E.O., Bensbih, M., El-Moussaoui, N., Idaomar, M., Abrini, J., 2013. Antagonist effect of Enterococcus durans E204 isolated from camel milk of Morocco, against Listeria monocytogens CECT 4032 in skimmed milk. Life Sci. J. 10(2), 2678-2683.
Khay, E.O., Idaomar, M., El-Moussaoui, N., Abrini, J., 2014. Application of a bacteriocin-like inhibitory substance producing Enterococcus durans E204 strain, isolated from camel milk, to control Listeria monocytogenes CECT 4032 in goat jben. Ann. Microbiol. 64(1), 313-319.

Khay, E.O., Idaomar, M., Pastrana-Castro, L.M., FajardoBernárdez, P., Skali-Senhaji, N., Abrini, J., 2011. Antimicrobial activities of the bacteriocin-like substances produced by lactic acid bacteria isolated from Moroccan dromedary milk. Afr. J. Biotechnol. 10(51), 10447-10455.

Klaenhammer, T.R., 1988. Bacteriocins of lactic acid bacteria. Biochimie. 70(3), 337-349.

Kumar, A., Shukla, R., Singh, P., Prasad, C.S., Dubey, N.K., 2008. Assessment of Thymus vulgaris L. essential oil as a safe botanical preservative against post harvest fungal infestation of food commodities. Innov. Food Sci. Emerg. Technol. 9(4), 575-580.

Mahboubi, M., Haghi, G., 2008. Antimicrobial activity and chemical composition of Mentha pulegium L. essential oil. J. Ethnopharmacol. 119(2), 325-327.

Majtan, J., 2014. Honey: an immunomodulator in wound healing. Wound Repair Regen. 22(2), 187-192.

Manyi-Loh, C.E., Clarke, A.M., Ndip, R.N., 2011. An overview of honey: therapeutic properties and contribution in nutrition and human health. Afr. J. Microbiol. Res. 5(8), 844-852.

Marzouk, B., Ben-Hadj-Fredj, M., Chraief, I., Mastouri, M., Boukef, K., Marzouk, Z., 2008. Chemical composition and antimicrobial activity of essential oils from Tunisian Mentha pulegium L. J. Food Agri. Environ. 6(2), 78-82.

Molan, P.C., 2002. Re-introducing honey in the management of wounds and ulcers-theory and practice. Ostomy Wound Manag. 48(11), 28-40.

Oryan, A., Khalafi-Nezhad, A., Toloo, N., Soltani-Rad, M.N., 2007. Effects of 4-chloro-2,6-bis-(2-hydroxyl-benzyl)phenol on healing of skin wounds and growth of bacteria. J. Vet. Med. Sci. 54(10), 585-591.

Oryan, A., Zaker, S.R., 1998. Effects of topical application of honey on cutaneous wound healing in rabbits. Zentralbl Veterinarmed A. 45(3):181-208.

Ouakouak, H., Chohra, M., Denane, M., 2015. Chemical composition, antioxidant activities of the essential oil of Mentha pulegium L, South East of Algeria. Int. Lett. Nat. Sci. 39, 49-55.

Ouedrhiri, W., Bouhdid, S., Balouiri, M., El-Ouali-Lalami, A., Moja, S., Ouazzani-Chahdi, F., Greche, H., 2015. Chemical composition of Citrus aurantium L. leaves and zest essential oils, their antioxidant, antibacterial single and combined effects. J. Chem. Pharm. Res. 7(1), 78-84.

Rodriguez, B.A., Mendoza, S., Iturriga, M.H., CastañoTostado, E., 2012. Quality parameters and antioxidant and antibacterial properties of some Mexican honeys. J. Food Sci. 77(1), 121-127.

Sharif, S., Singh, M., Kim, S.J., Schaefer, J., 2009. Staphylococcus aureus peptidoglycan tertiary structure from carbon-13 spin diffusion. J. Am. Chem. Soc. 131(20), 7023-7030. 
Singh, M.P., Chourasia, H.R., Agarwal, M., Malhotra, A., Sharma, M., Sharma, D., Khan, S., 2012. Honey as complementary medicine: a review. Int. J. Pharma Bio. Sci. 3(2), 12-31.

Sitzmann, J., Habegger, R., Schnitzler, W.H., Grassmann, J., 2014. Comparative analysis of antioxidant activities of fourteen Mentha essential oils and their components. Chem. Biodivers. 11(12), 1978-1989.

Smith, J.M., Tang, C.M., Van-Noorden, S., Holden, D.W., 1994. Virulence of Aspergillus fumigatus double mutants lacking restriction and an alkaline protease in a low-dose model of invasive pulmonary aspergillosis. Infect. Immun. 62(12), 5247-54.
Vorlova, L., Karpiskova, R., Chabiniokova, I., Kalabova, K., Brazdova, Z., 2005. The antimicrobial activity of honeys produced in the Czech Republic. Czech J. Anim. Sci. 50(8), 376-384.

Wasiak, J., Cleland, H., Campbell, F., Spings, A., 2013. Dressings for superficial and partial thickness burns Review. Cochrane Data. Syst. Rev. 3, CD002106. DOI: 10.1002/14651858.CD002106.pub4.

Yaghoobi, R., Kazerouni, A., Kazerouni, O., 2013. Evidence for clinical use of honey in wound healing as an anti bacterial, anti-inflammatory anti-oxidant and anti-viral agent: A review. Jundishapur J. Nat. Pharm. Prod. 8(3), 100-104.

\section{How to cite this article:}

Khay, E. O., Bouyahya, A., El Issaoui, K., Zinebi, S., Abrini, J., 2016. Study of synergy between Mentha pulegium essential oil, honey and bacteriocin-like inhibitory substance E204 against Listeria monocytogenes CECT 4032 and Escherichia coli K12. Int. J. Curr. Res. Biosci. Plant Biol. 3(11), 29-35.

doi: http://dx.doi.org/10.20546/ijcrbp.2016.311.005 